\title{
Educação do Campo e interdisciplinaridade: descrição de propostas metodológicas desenvolvidas no município de Canoinhas-SC
}

\section{Field Education and interdisciplinarity: description of methodological proposals developed in the municipality of Canoinhas-SC}

\author{
Letícia Paludo Vargas (letipvargas@gmail.com) \\ Professora Visitante no Programa de Pós-Graduação em Desenvolvimento Regional da Universidade do \\ Contestado (UnC) Campus Canoinhas, SC.
}

\author{
Alexandre Assis Tomporoski (alexandre@unc.br) \\ Professor do Programa de Pós-Graduação em Desenvolvimento Regional da Universidade do Contestado \\ (UnC) Campus Canoinhas, SC.
}

Resumo: O presente trabalho descreve as ações executadas durante o ano letivo de 2019 no âmbito do Projeto de Extensão Universitária: "Programa de Formação dos Técnicos Agrícolas e Agroecológicos de Canoinhas/SC - Educação do Campo". O objetivo do projeto foi resgatar e elaborar, de forma participativa, diversas práticas metodológicas interdisciplinares que vem sendo desenvolvidas pelo Programa Interdisciplinar de Educação do Campo na Rede Municipal de Ensino de Canoinhas. As temáticas trabalhadas nas turmas do pré-escolar ao $9^{\circ}$ Ano são pré-definidas nos planejamentos anuais, de acordo com o currículo escolar básico, entretanto, podem ser reorganizadas dependendo das necessidades, especificidades e do planejamento estratégico fundamentado nos eixos norteadores do Programa: humano e agrossilvipastoril, consideradas as demandas regionais relacionadas às atividades agropecuárias. $\mathrm{O}$ resultado foi a construção de um material informativo, com direcionamentos das atividades curriculares à Educação Básica, contextualizadas com a Educação do Campo. No decorrer do projeto, a equipe apresentou ferramentas possíveis de serem implementadas nas escolas, como, por exemplo: caderno da realidade, colocação em comum, atendimento individualizado, visita às famílias, projeto profissional, dentre outras.

Palavras-chave: Educação do Campo; Desenvolvimento Rural; Formação continuada.

Abstract: The present work describes the actions within the scope of the Extension Project: "Programa de Formação dos Técnicos Agrícolas e Agroecológicos de Canoinhas - Educação do Campo", during academic year 2019. The Project objective was to rescue and elaborate, in a participatory way, several interdisciplinary methodological practices that have been developed by the Programa Interdisciplinar de Educação do Campo of Canoinhas. The themes worked in the classes from pre-school to the 9th grade are pre-defined in the annual plans, according to the basic school curriculum, however, they can be reorganized based on the needs and specificities and the strategic planning based on the Program's guiding: human and agrosilvipastoral, observing the regional demands related to agricultural activities. The result was the construction of an informative material with guidelines for curricular activities for Basic Education, contextualized with Rural Education. During the project, the team presented 
possible tools to be implemented in schools, such as, for example: reality notebook, common placement, individualized service, visit to families, professional project, among others.

Keywords: Rural Education; Rural Development; Continuing Education.

\section{INTRODUÇÃO}

O presente artigo visa apresentar o trabalho desenvolvido no decorrer do ano de 2019 entre o Programa de Mestrado em Desenvolvimento Regional (PMDR), da Universidade do Contestado (UnC), o Curso de Pedagogia da mesma instituição e o Programa Interdisciplinar de Educação do Campo, gerenciado pela Secretaria Municipal de Educação de Canoinhas, SC, com o objetivo de suprir a necessidade de formação continuada na área de Educação do Campo.

A proposta, constituída no Projeto de Extensão intitulado: "Programa de Formação dos Técnicos Agrícolas e Agroecológicos de Canoinhas - Educação do Campo" elenca atividades de formação para os Técnicos Agrícolas e Agroecológicos do município de Canoinhas que atuam na Educação do Campo. Esse projeto de Extensão teve a finalidade de promover a troca de experiências entre os profissionais e os pesquisadores sobre a temática da Educação do Campo, com a possibilidade de elaboração conjunta de propostas pedagógicas, articuladas ao currículo das escolas e integradas à educação do campo.

Para a implementação do projeto, partiu-se do pressuposto de que o processo de educar abrange muito mais que ensinar a ler, escrever e contar. Nesse sentido, a educação deve construir, de forma democrática e conjunta, conhecimentos que sirvam de base para a vida dos educandos. Esta democracia educacional não consiste apenas em saber que o aluno adquiriu conhecimento, mas, também, em respeitar a autonomia do educando, enquanto detentor de seus conhecimentos dentro de um contexto próprio (FREIRE, 2007).

Justifica-se a proposta de trabalho em virtude do compromisso da Universidade em promover a educação em todas as esferas, possibilitando o desenvolvimento em sua região de atuação, ratificando a indissociabilidade entre o ensino, pesquisa e extensão, e melhorando substancialmente a qualidade de vida dos cidadãos. Nesse contexto, o projeto de pesquisa pretendeu viabilizar a formação continuada dos Técnicos Agrícolas 
e Agroecológicos vinculados à Educação do Campo no município de Canoinhas-SC. Por isso, no presente trabalho, serão descritos os resultados obtidos durante um ano de realização do projeto, mediante caracterização das escolas localizadas no meio rural do município de Canoinhas e as atividades desenvolvidas no decorrer do ano, incluindo a descrição das práticas metodológicas interdisciplinares que foram implementadas nas escolas do campo.

\section{PROCEDIMENTOS METODOLÓGICOS}

A delimitação geográfica do município de Canoinhas/SC circunscreve-se a $1.145 \mathrm{~km}^{2}$ (IBGE/2010). Entretanto, sua predominância ocorre na área rural, totalizando $1.115 \mathrm{~km}^{2}$, enquanto a área urbana ocupa somente $30 \mathrm{~km}^{2}$ do seu território.

A Educação do Campo no município de Canoinhas é desenvolvida em todas as escolas, situadas no campo, e contempla a educação básica (educação infantil e ensino fundamental I e II), de acordo com as unidades escolares da rede municipal de ensino. $\mathrm{O}$ Programa Interdisciplinar de Educação do Campo, criado no ano de 2005 pela Secretaria Municipal de Educação, além das escolas situadas no campo, integra mais duas escolas situadas na área urbana. São escolas núcleos, resultado do processo de municipalização e nucleação do ensino (1997 e 1998). Essas escolas núcleos possuem proporção superior a $40 \%$ de alunos matriculados oriundos do campo. Dessa forma, o Programa contempla quatorze escolas e registrou, no Educacenso/2019, um total de 1.940 alunos - 30,55\% do total de 6.349 alunos da Rede Municipal de Ensino.

A implantação do Programa Interdisciplinar de Educação no Campo originou-se pela iniciativa da Secretaria Municipal de Educação (SME) /Canoinhas-SC, atendendo às solicitações formalizadas por representantes das localidades rurais, bem como, pela análise dos diagnósticos realizados pelo Projeto de Desenvolvimento Rural Sustentável - Microbacias II. Esse projeto (2002-2009) objetivou minimizar a pobreza rural, através de ações integradas que visavam o desenvolvimento econômico, ambiental e social do meio rural catarinense, proporcionando assistência técnica e extensão rural nos municípios e capacitação para agricultores, indígenas, líderes, jovens e técnicos (SC RURAL, 2017). 
Para implementar as práticas agrícolas e ambientais, integrando a educação do campo ao currículo básico, o município conta com oito instrutores agrícolas em equipes pedagógicas e administrativas, convidados a participar do referido Projeto de extensão.

As atividades foram desenvolvidas em três etapas, que ocorreram nos meses de maio, agosto e outubro de 2019, com a participação de representantes dos proponentes do projeto e dos oito instrutores agrícolas das escolas do campo da rede municipal de ensino.

Inicialmente, foi realizado um diagnóstico nas Escolas do Campo, por meio de um roteiro semiestruturado versando sobre: formação técnica, escola de vínculo, metodologia de trabalho, temáticas trabalhadas, participação dos estudantes em atividades teóricas e práticas e nas disciplinas e interação das famílias/comunidade com o ambiente escolar.

A abordagem utilizada foi a qualitativa, que, de acordo com Richardson (2017), permite compreender e classificar os processos dinâmicos vivenciados por grupos sociais, contribuir para transformações em determinado grupo e possibilitar o entendimento das particularidades do comportamento dos entrevistados.

Durante o desenvolvimento das etapas, foi utilizada a metodologia da roda de conversa, que, conforme Melo e Cruz (2014), tem a característica de permitir que os participantes expressem concomitantemente suas impressões, conceitos, opiniões e concepções sobre determinado tópico, propiciando o trabalho reflexivo sobre o tema proposto, nesse caso específico, as práticas pedagógicas relacionadas às Escolas do Campo. Na sequência, em determinado encontro, eram encaminhadas atividades a serem realizadas nas escolas, cujas informações seriam compartilhadas no próximo encontro.

No decorrer das atividades, a equipe do projeto de extensão apresentou práticas aplicáveis às escolas do campo, tais como: colocação em comum ${ }^{1}$, atendimento individualizado, caderno da realidade, visita às famílias, projeto profissional, dentre outras. A ideia diretriz era de que os instrutores, juntamente com a equipe, refletissem sobre novas possibilidades metodológicas e elaborassem estratégias adaptadas à

${ }^{1}$ É um momento que ocorre nas primeiras aulas da turma na semana, onde os jovens explicam o que foi realizado em suas propriedades referente às atividades práticas (agropecuárias). Essa metodologia é mais utilizada em escolas do campo que trabalham com a pedagogia da alternância. 
educação do campo municipal. Paralelamente, foram reelaboradas metodologias interdisciplinares suscetíveis de aplicação à Educação do Campo, que serão apresentadas nos resultados deste trabalho.

\section{RESULTADOS E DISCUSSÃO}

\section{O Projeto de Extensão: Programa de Formação dos Técnicos Agrícolas e} Agroecológicos de Canoinhas - Educação do Campo

Ao realizar uma breve abordagem a respeito da Educação do Campo, entende-se que, de acordo com Arroyo (2012), a educação do campo objetiva diminuir as migrações do campo para a cidade, com o incentivo às atividades produtivas e promovendo a melhoria das condições de vida da população que ali reside. Além disso Arroyo, Caldart e Molina (2009) consideram que a diversidade dos povos do campo, a situação histórica particular, os recursos disponíveis e os anseios daqueles que vivem no campo devem ser levados em consideração para a construção do currículo das escolas do campo.

Dentro dessa perspectiva, e objetivando melhorias para a Educação do Campo, na primeira etapa do projeto de extensão, foram apresentadas as atividades desenvolvidas pelos instrutores agrícolas da Educação do Campo, que incluíam o trabalho prático nas escolas rurais, com destaque para a participação dos alunos, a organização do trabalho e a participação dos pais e da comunidade no meio escolar.

Com relação ao perfil dos profissionais, apenas um, dos oito instrutores agrícolas, possui curso técnico em Agroecologia; os demais são técnicos em Agropecuária. Os resultados demonstram ainda que 75\% (6/8) dos instrutores possuem curso superior completo ou estão finalizando, destes, 37,5\% em cursos na área de Ciências Agrárias.

Acerca das principais temáticas desenvolvidas em sala de aula, os instrutores agrícolas declararam que os temas geradores do currículo escolar voltado à Educação do Campo (pré-escolar ao nono ano do ensino fundamental) já são pré-definidos, e que todos seguem a base curricular, que contém temáticas relacionadas à água, ao solo, às atividades agropecuárias, dentre outros. $\mathrm{O}$ instrutor que tem formação em Agroecologia declarou que prioriza o desenvolvimento das atividades pedagógicas práticas dentro dos pressupostos Agroecológicos. 
A respeito da possibilidade de os estudantes interferirem nos temas geradores, todos os entrevistados destacaram que os saberes populares são levados em consideração. Tal assertiva é evidenciada pelo depoimento do Instrutor 2, quando diz: "Não só podem, como devem propor temas relacionados à sua realidade, o seu contato social, no que tange ao desenvolvimento da agricultura sustentável”. Contudo, alguns destacaram que podem ser propostos novos assuntos, desde que se enquadrem nos temas geradores.

No que concerne às turmas que sobressaem, todas têm suas especificidades, porém, as dos anos finais compreendem e assimilam mais os conteúdos relativos às atividades agropecuárias. Com relação ao funcionamento das atividades práticas e intervenções em sala de aula, os professores buscam adaptar os conteúdos com a realidade do campo. São elencados conteúdos relacionados com diferentes temáticas, divididos em eixos: humano e agrossilvipastoril. Nos dois eixos, são trabalhadas diversas temáticas, tais como: saúde, animais, valores, alimentação saudável, horta, plantas medicinais, higiene, poluição, turismo rural, diversificação das atividades produtivas e Agroecologia.

A participação do núcleo familiar nas atividades escolares foi relatada pelos instrutores agrícolas, explicando que os pais participam, integrando-se às atividades e, em muitos casos, acompanhando o trabalho dos professores e incentivando os estudantes a participarem de projetos vinculados à Educação do Campo. A presença dos pais também ocorre nas atividades da comunidade: eventos, feiras agropedagógicas e outros projetos.

No que se refere a possibilidade de orientação profissional aos alunos do nono ano, os instrutores destacaram que embora não se tenha um programa de orientação consolidado, os estudantes são orientados com base nas temáticas do empreendedorismo, cooperativismo, orientação para o mercado de trabalho, diversificação das atividades na propriedade e atividades vocacionais. Além disso, as atividades trabalhadas no ambiente escolar geralmente são replicadas nas propriedades pelos estudantes, como, por exemplo, os canteiros, compostagem, plantas medicinais, dentre outros. 
As intervenções dos instrutores ocorrem em diversas disciplinas regulares, por meio de um trabalho conjunto com os professores, especialmente nas disciplinas de ciências, arte, matemática, geografia e português. A proposta curricular estimula a integração das atividades pedagógicas práticas com todas as disciplinas do currículo. Porém, um dos instrutores destacou que, na escola em que trabalha (anos iniciais), por ter apenas um professor em sala de aula, o planejamento já é realizado conjuntamente entre professor e técnico, considerando o conteúdo a ser desenvolvido por ambos.

Em referência a possibilidade de visitar as famílias em suas propriedades, os técnicos informaram que ocorre em poucas ocasiões, pois o período de trabalho em sala de aula é integral, não havendo muito tempo disponível. As atividades práticas realizadas com as famílias dos agricultores acontecem em alguns momentos, com determinadas temáticas, e envolvem procedimentos de observações e pesquisas.

Por fim, os técnicos destacaram as diversas parcerias consolidadas por meio de projetos, com instituições externas à escola, dentre elas: Empresa de Pesquisa Agropecuária e Extensão Rural de Santa Catarina (Epagri), Companhia Integrada de Desenvolvimento Agrícola de Santa Catarina (Cidasc), Universidade do Contestado (UnC), Instituto Federal de Santa Catarina (IFSC), Universidade Federal de Santa Catarina (UFSC), Serviço Nacional de Aprendizagem Rural (Senar), Associação dos Fumicultores do Brasil (Afubra), Empresa WestRock, $e$ outras entidades ligadas ao desenvolvimento rural e sustentabilidade ambiental.

Ao final da primeira etapa, com base na metodologia da roda de conversa e discussão em grupo, foi proposta a elaboração conjunta de novas práticas pedagógicas. Tais práticas, passíveis de serem operacionalizadas, deveriam ser examinadas e debatidas juntamente com a Equipe Pedagógica das Escolas do Campo, e socializadas no grupo durante o próximo encontro com os participantes da formação continuada.

$\mathrm{Na}$ segunda etapa (agosto/2019), foram debatidos os conceitos de multidisciplinaridade, interdisciplinaridade e transdisciplinaridade e quais as possibilidades de trabalho nas Escolas do Campo de Canoinhas. O debate possibilitou que os instrutores agrícolas descrevessem o trabalho que desenvolvem com os estudantes e como são realizadas as práticas pedagógicas pelos professores e instrutores nas escolas. Na mesma ocasião, foram definidas algumas estratégias de trabalho para a 
Educação do Campo, colocadas em prática no decorrer do ano letivo pelos instrutores agrícolas. Desse modo, começavam a surgir os primeiros resultados do Projeto de Extensão.

Na terceira etapa (outubro/2019), foram apresentados os resultados da utilização do "Caderno das atividades técnicas", metodologia escolhida no encontro anterior, e trabalhada pelos instrutores agrícolas durante o período. De acordo com os instrutores, a utilização do Caderno deixou os estudantes mais atentos ao desenvolvimento das atividades, pois tinham que descrever o que foi realizado nas aulas práticas, respondendo a perguntas, como: Qual a atividade desenvolvida? Para que serve? Como é realizada?

O objetivo do Caderno consiste em retomar e relatar o que foi realizado, inclusive criando um registro para que os conhecimentos acessados na escola possam ser aplicados nas propriedades rurais. Esse procedimento metodológico foi aplicado em todas as turmas. Nas séries iniciais, inclusive, utilizavam desenhos para explicar, pois ainda estão se familiarizando com a escrita. Nos anos finais, anotam os passos detalhadamente, com auxílio do instrutor. O caderno pode ser levado para casa pelos estudantes, para que as técnicas aprendidas na escola sejam replicadas na propriedade da família. Ainda no que tange à terceira etapa, foi apresentada a iniciativa para elaboração de um documento que expusesse as práticas pedagógicas interdisciplinares para a Educação do Campo.

Durante o ano letivo, além das três etapas de formação, foram realizadas diversas visitas nas escolas do campo do município, com o objetivo de conversar com as pedagogas, observar o trabalho dos instrutores agrícolas e as atividades práticas desenvolvidas com os estudantes, possibilitando a proposição de novas metodologias.

Durante os encontros, também foram apresentados alguns modelos de práticas pedagógicas utilizadas pelos professores e instrutores agrícolas nas Escolas do Campo, que culminou na publicação do livro: "Práticas Pedagógicas Interdisciplinares para a Educação do Campo" (BLAKA; VARGAS, 2019), objetivando a sua utilização como um documento base a ser empregado nas Escolas para consulta e direcionamento das atividades pedagógicas e técnicas, dada a rotatividade anual de educadores. 
As atividades curriculares nas escolas do campo são direcionadas com base na definição das temáticas, desenvolvidas por nível/ano/disciplina e específicas para a Educação do Campo municipal. Estabelecidas as temáticas, a ideia diretriz é que o estudante possa desenvolver competências/habilidades com a realização das atividades.

Sob essa perspectiva, os conteúdos para cada turma, desde a educação infantil, até o nono ano do ensino fundamental, são os seguintes: I) Educação infantil (préescolar): semeadura, germinação e plantio; II) Primeiro Ano: meio ambiente, reciclagem e compostagem; III) Segundo ano: horta e jardinagem, tipos de horta, canteiros e alimentação saudável; IV) Terceiro ano: plantas medicinais e temperos caseiros; V) Quarto ano: água, nascentes, pluviômetro, cisterna e animais; VI) Quinto ano: solos, fruticultura e florestas (cultivo, manejo e mata ciliar); e animais (Projeto Sanitarista Júnior (CIDASC ${ }^{2}$ ); VII) Sexto ano: agricultura, solos, água e ar; VIII) Sétimo ano: sustentabilidade, meio ambiente, economia e permanência do jovem no campo; IX) Oitavo ano: adubação, genética, nutrição humana, empreendedorismo e permanência do jovem no campo; X) Nono ano: associativismo/cooperativismo, pesquisa, tecnologia e permanência do jovem no campo.

As temáticas e os conteúdos são adaptados conforme conteúdos regulares préestabelecidos pelas Diretrizes Curriculares da Educação Infantil e Ensino Fundamental e trabalhados em conjunto com atividades diversificadas. Além das temáticas descritas anteriormente, são elencadas sugestões com práticas pedagógicas, e estão disponíveis no material didático elaborado durante o ano de 2019, no decorrer do projeto de extensão.

As aulas são planejadas semanalmente e conjuntamente entre professores e instrutor agrícola, desenvolvendo a teoria e a prática, de acordo com os conteúdos curriculares propostos para cada nível de ensino. O professor da sala de aula é incumbido de acompanhar todas as atividades, para que possa dar continuidade nas aulas subsequentes às temáticas abordadas.

Algumas metodologias são aplicadas de modo abrangente, haja vista que podem ser adaptadas para quase todos os níveis de ensino. Destacam-se: 1) elaboração de projetos interdisciplinares; 2) valorização de produtos agrícolas; 3) atividades de

${ }^{2}$ O Projeto objetiva sensibilização e consciência ambiental, permitindo às crianças desenvolverem valores e competências para o exercício da cidadania, tornando-se multiplicadoras das ações de defesa agropecuária, com conhecimentos que contribuirão para a melhoria da produção de alimentos seguros e a qualidade de vida no campo (CIDASC, 2020). 
educação ambiental; 4) visitas técnicas/dias de campo; 5) anotações das atividades no caderno de campo; 6) intervenção externa (palestrante, membro da comunidade, etc.); 7) intervenção do instrutor agrícola (em sala de aula, nas disciplinas regulares); 8) elaboração de relatórios das visitas técnicas; 9) construção de um jardim das sensações; 10) entrevistas relacionadas ao campo; 11) catalogação e monitoramento de plantas; 12) trabalho com medidas agrárias e paisagismo; 13) orientação profissional ${ }^{3}$ etc.

Outros trabalhos como o de Moro et al. (2019), descrevem propostas com aplicabilidade, que inclusive podem beneficiar a comunidade escolar, como o caso da construção de um biodigestor, envolvendo as disciplinas de biologia, física e química.

Com o intuito de acompanhar os resultados pertinentes à atuação dos professores e equipes administrativas e pedagógicas nas Escolas do Campo, realiza-se avaliação ao final de cada ano letivo. Essa avaliação dos resultados das atividades pedagógicas desenvolvidas durante o ano letivo é respaldada na concepção de Nóvoa, (2017, p. 11), que salienta que devem ser adaptados "os esforços para a criação de um novo ambiente escolar, um ambiente de aprendizagem vivo e estimulante, de trabalho em comum sobre o conhecimento, um ambiente de curiosidade científica e de aprendizagem".

Dessa forma, a Coordenação do Programa realiza essa avaliação desde o início das atividades, no ano de 2006, enviando às escolas um formulário com questões a serem avaliadas, com base em reflexões sobre a organização do projeto pedagógico e curricular, a interação entre os educadores na realização das atividades e dos temas/conteúdos, contextualizados com as propostas da Educação do Campo. O objetivo é coletar dados que possibilitem avaliar o planejamento e as ações pedagógicas no contexto escolar.

Os índices apurados no decorrer dos anos demonstram a efetividade do trabalho realizado nas escolas. Esse fato pode ser comprovado com base nas respostas obtidas entre os anos de 2006 (quando ainda era Projeto) a 2019. No ano de 2006, cerca de $40 \%$ dos profissionais das Escolas do Campo compreendiam que o Projeto era considerado “ótimo”. Já no ano de 2019, o percentual subiu para 92,02\%, o que reafirma a importância da contextualização dos temas do currículo básico direcionados à Educação do Campo.

\footnotetext{
${ }^{3}$ A descrição das atividades mencionadas encontra-se disponível na publicação de Blaka e Vargas (2019), e, também, por meio dos relatórios e planejamentos de ensino da Educação do Campo.
} 
A coordenação do Programa, de acordo com as avaliações, planeja ações/metodologias em conjunto com a equipe pedagógica da SME para aperfeiçoar as atividades desenvolvidas durante o ano letivo. Constata-se que nas escolas do campo, os professores estão obtendo êxito em contextualizar os conhecimentos curriculares com as propostas do Programa, baseadas nos eixos norteadores e nas atividades práticas.

Percebe-se que nas comunidades escolares ainda há desafios a serem superados a cada ano. As inovações e diferentes formas de integração entre educadores para realização das ações pedagógicas necessitam ser construídas no interior de cada escola. Os mecanismos de avaliação e acompanhamento auxiliam o gestor escolar, a equipe de trabalho e a SME a promover adequações aos conteúdos relacionados à educação do campo, além de adaptações às atividades realizadas.

\section{CONSIDERAÇÕES FINAIS}

Esse relato do Projeto de Extensão realizado durante o ano de 2019 demonstra que a Educação do Campo, no município de Canoinhas, tem suas atividades estruturadas a mais de uma década, com o funcionamento das escolas do campo ocorrendo de forma planejada e integrada através do Programa Interdisciplinar de Educação do Campo, coordenado pela SME, mediante atuação de professores e técnicos agrícolas nas escolas.

Convém destacar que novas ferramentas de ensino e aprendizagem podem ser planejadas para a Educação do Campo, por meio de um processo de construção participativa entre os técnicos, equipe pedagógica e grupo de formação. Além disso, entende-se que a referida proposta de Extensão ratifica seu compromisso com a educação, com a população rural e com o processo de desenvolvimento na região de atuação, que geograficamente apresenta preponderância de indivíduos oriundos do campo, objetivando a excelência em ensino, pesquisa e extensão e promovendo melhoria na qualidade de vida dos cidadãos.

Deste modo, considera-se de extrema importância a participação regular dos instrutores agrícolas no Programa de Formação que foi proposto durante o ano de 2019, e em outros programas de formação futuros, para que possam ser disponibilizados subsídios pedagógicos para a interação e construção participativa de novas experiências 
entre professores, instrutores agrícolas e profissionais de apoio pedagógico, integrando a teoria e a prática em uma abordagem interdisciplinar.

A troca de experiências bem-sucedidas nas escolas do campo permite o aprimoramento contínuo dos trabalhos, que já vem obtendo êxito nas escolas integradas à Educação do Campo no município de Canoinhas. Almeja-se que o material elaborado durante o ano de 2019 possa ser aplicado em outros municípios, de tal modo que a experiência do Programa Interdisciplinar de Educação do Campo, considerada uma política pública municipal, possa ser utilizada como referência em regiões que apresentam territórios predominantemente agrícolas, com perfis de educação do campo similares.

\section{REFERÊNCIAS}

ARROYO, M. G. Diversidade. In: Dicionário da Educação do Campo. São Paulo: Expressão Popular, 2012.

ARROYO, M. G.; CALDART, R. S.; MOLINA, M. C. (org.). Por uma educação do campo. 4. ed. Petrópolis: Vozes, 2009.

BLAKA, R. F. C; VARGAS, L. P. Práticas pedagógicas interdisciplinares para a educação do campo. [recurso eletrônico - E-book] - Mafra, SC: Ed. da UnC, 2019. Disponível em: <https://www.unc.br/biblioteca/ebook/Ebook_Praticas_pedagogicas_int erdisciplinares_para_a_Educacao_do_Campo.pdf.> Acesso em 10 maio 2020.

COMPANHIA INTEGRADA DE DESENVOLVIMENTO AGRÍCOLA DE SANTA CATARINA (CIDASC). Projeto Sanitarista Junior encerra ano letivo de 2019 com 95 escolas parceiras no Estado. Disponível em: <http://www.cidasc.sc.gov.br/blog /2020/01/07/projeto-sanitarista-junior>. Acesso em 28 jul 2020.

FREIRE, P. Pedagogia da Autonomia: saberes necessários à prática educativa. 35 ed. São Paulo: Paz e Terra, 2007.

MELO, M. C. H. de; CRUZ, G. de C. Roda de conversa: uma proposta metodológica para a construção de um espaço de diálogo no ensino médio. Imagens da Educação, v. 4, n. 2, p. 31-39, 2014.

MORO, F. T. et al. Construção de um biodigestor: uma proposta de ensino interdisciplinar para escolas do campo. Revista Insignare Scientia. v. 1. 2, n. 1. Jan/abr, 2019.

NÓVOA, A. A Escola do século XXI. Base Nacional Comum Curricular. Material para o professor - Por dentro da BNCC - Ed. Moderna; v. 4, p. 10-13, 2017.

RICHARDSON, R. J. Pesquisa social. Métodos e técnicas. 4. Ed. São Paulo: Atlas, 2017.

SANTA CATARINA. Projeto Prapem/Microbacias 2 (2002 a 2009). SC Rural. 2017. Disponível em: 〈http://www.scrural.sc.gov.br/?page_id=5>. Acesso em 10 out 2019. 